\title{
Carta Abierta a Pablo Neruda
}

Querido Pablo, qué bueno es que los rituales de la edición me ha. yan dado este correa vertiginoso, este buzón de miles de facetas don. de una carta para ti será también para tantos otros. Detesto los prólogos o las introducciones pero ya ves, ocurre a veces que las costumbres y las rutinas despiertan a una nueva vida, como el gesto mecánico y absurdo de estrecharse la mano (¿será cierto que nació del sentimiento contrario, de la prueba de que no se estaba ocultando una daga entre los dedos?) puede volverse encuentro y comunión, diálogo de la piel que se reconoce y se comprende por debajo de las palabras, poesía del tacto primordial, signo de la amistad de los hombres. $Y$ ocurre entonces que después de libaciones necesarias y propiciatorias que como chileno de verdad comprenderás harto, te pongo estas líneas para intentar la doble carambola de hacerte una carta que a la vez sirva de algo a los lectores que han de entrar en este libro por la vía del francés.* Siempre me ha gustado complicar las reglas del juego, puesto que lo contrario, lo lineal y directo, es aburrido; admitirás, hermano, que resulta a la vez difícil y exaltante hablarte mientras hablo a lectores que, salvo excepciones, no saben de los litorales pacíficos, no vieron nunca las estrellas sobre Temuco o sobre Isla Negra, y entonces sî, entonces vale la pena escribir donde una zona en la que la mano y la palabra juegan por cuenta propia un billar de muchas bandas. Ahora va a suceder que cuando digo Pablo también estoy diciendo Paul y Christiane y Robert, todos los nombres de pila de los que estén leyendo mi carta, el hermoso concilio invisible, tú en Chile o en París, yo en París o en Viena (de hecho en Viena, Pablo, pero vaya a saber si esta carta no se acaba en Londres o en Lima o en un tren

* Esta "Carta abierta" fue escrita por Julio Cortázar como Introducción a la versión francesa de Residencia en la tierra, que publicará Gallimard en la Colección "Poèsie". Agradecemos al autor el envío del texto original español para este número de la R. I. 
que corre a lo ancho de la noche, tenemos tiempo y sed, tenemos páginas y vino), y Christiane en Poitiers, Fernand en Limoges, Claude en París, todos unidos fuera del tiempo y del espacio por esta operación tan vieja y tan dulce de escribir desde el amor y la esperanza, porque contra viento y marea el hombre salva y defiende un territorio común, una zona de encuentro donde maravillosamente renunciamos a la veda y al secreto, donde un poema o una pintura o un solo de trompeta valen como el encuentro de los cuerpos de la mujer y el hombre, como el silbar de las golondrinas en la última luz de la tarde, como el temblor de un trigal que amé en la isla Tenglo allá por el año cuarenta y dos cuando conocí tu Chile y anduve por sus tierras y sus islas y en una plaza de Valparaíso, una noche de calor y de tristeza, leí sentado en un banco tu España en el corazón que luego habría de entrar en la Tercera Residencia pero que entonces efa un libro de grandísimo formato, tan incómodo de llevar salvo cuando ganaba el pecho, la región solapada y crepuscular donde acaso van a morir de verdad los elefantes y los pájaros.

Escucha, Pablo, de sobra sé, de sobra lo he leído, que tu camino de hombre y de poeta te ha alejado de las dos primeras Residencias, que las has apartado de ti con el gesto que creías necesario, y que tu poesía pos. terior, ese gran canto general que sigue fluyendo de tu vida cuenta más que ellas en tu sentimiento de luchador y de sudamericano. Está bien, hermano, no seré yo quien te niegue la razón de ese deslinde, está bien que la búsqueda y el encuentro de un contacto con tu pueblo y con todos los pueblos te distancie de esos poemas. Vivimos un tiempo violento, vivimos entre aletazos nucleares y genocidios fríamente orquestados desde computadoras y pentágonos; más que nunca el poeta está desnudo al alba de cada día, pero por estar desnudo está más libre que nunca, o bien no es más que uno de los lamentables histriones que siguen vistiendo el frac de un humanismo hecho pedazos por tanta larga marcha, por tanto arrozal de luz, por tanto azúcar contra la noche del dólar. Y entonces Pablo Neruda mira hacia atrás, se mira como también otros hemos aprendido al fin a mirarnos y rechaza su antiguo tiempo ptolemaico, la obra escrita que lentamente, maravillosamente giró por años y años en torno a un yo que aún no había accedido al thi, anterior a la intuición copernicana, al reclamo revolucionario universal que a tantos nos ha expulsado de nosotros mismos como en un autonacimiento necesatio y atroz, "entre gritos y lágrimas y heces". Vaya si lo sabemos, Pablo, vaya si las primeras Residencias son el pasado, los últimos peldaños antes del salto que acaba con el individualismo egocéntrico para acceder a esa otra manera de vivirse hombre, inmerso y poroso y partícipe, el hombre que interroga y agrede 
para encontrar las respuestas que lo integren en su contorno, el hombre que hace frente a la circunstancia para desnudarla de mentira a ráfagas de verbo, ya no solamente por él aunque siempre por él, ya no solamente el poema aunque siempre el poema: otra poesía ha nacido en nuestro tiempo, su nombre es revolución y su libro es de vienta y de manos, de lecturas sin sofá, de encuentro en plena calle, la poesía no cambia y es dificil o fácil y se canta o se calla, pero lo que cuenta para nosotros ha cesado de ser privilegio original de mandarines latinoamericanos o europeos o yanquis, nada podrá jamás cambiar el acto poético, ese enfrentarse cara a cara con el mundo, pero la soledad del poeta no es ya la del esquema centrípeto, su soledad se sabe histórica y no meramente ontológica, el poema nace para ser más que un poema, piedra en el edificio de una futura humanidad desalienada, martillo o trago de agua en el taller multitudinario donde lentamente se empieza a modelar otra imagen del hombre en el planeta.

Entonces, Pablo, cómo negarte el derecho a que niegues, a que renuncies a esos poemas, esas criaturas "nacidas de un largo rechazo" como dices en "Sabor". Pero déjame hablar un momento, hermano, déjame mostrar a Christiane y a Raymond y a Robert, a todos los que acaso entran por primera vez y desde otra lengua en tu poesía, tantas cosas que por modestia callas. Si en la Tercera Residencia los lectores te encontrarán tal como te forjaste y te quisiste, tal como sigues siendo al término de tanto fabuloso libro, yo te digo y les digo que los poemas de las dos primeras Residencias contienen toda tu poesía futura y te contienen, lo creas o no, en tanto que poeta revolucionario. Vivimos un tiempo en el que la prostitución de la palabra vale como un arma insidiosa y terrible, y es así que términos como compromiso y contenido y otras consignas de esa laya se vuelven letales si se las usa mal, si una visión pragmática de la poesía las llena de intransigencia y de amenaza. Estoy harto, Pablo, de ese ranking latinoamericano de la poesía o de la narrativa en el que las adhesiones más tangibles - los temas, las demagogias, los simplismos, los indigenismos, lo que quieras - pasan a ser un indice revolucionario, un salvoconducto por las buenas conciencias y las consagraciones. En ese terreno, rechazar las primeras Resiliencias porque no se insertan explícitamente en su tiempo histórico es olvidar que sólo por ellas, gracias a esa terrible y maravillosa experiencia poética que fue dando esos poemas, pudiste tú salirte de ti mismo, entrar en la otredad armado de pies a cabeza, lúcido y seguro, y que sólo al término de esa larga, lenta exploración de tu contorno, alcanzaste la madurez que nos daría el Canto General y tanto más. Toco aquí un hecho grave, una brecha demasiado frecuente en la 
concepción revolucionaria de la literatura: el olvido ingenuo, cuando no la negación aviesa de ese difícil avance del escritor en sí mismo y en su instrumento de trabajo, las infinitas escalas de ese viaje que acabará ciñendo magallánicamente el mundo y hará del viajero de palabras un capitán de ideas, un jefe de hombres desde el verbo, un revolucionario desde cada poema que ahora será acto de vida, gesto político, disparo contra el enemigo. Pablo, parece estar escrito (cf. Mao) que los intelectuales desaparecerán tarde o temprano para ceder el lugar a otra manera colectiva de valerse de la inteligencia y la sensibilidad. Está bien, todo tiene su tiempo, y lo que cuenta es la justicia y el encuentro definitivo y planetario de los hombres. Pero si digo justicia, porque ésa es para mí la piedra de fuego de la revolución, cómo aceptar que se niegue o se ignore que poetas como tú no aparecieron de la noche a la mañana, que su avance fue lento y penoso y contradictorio; cómo aceptar que poetas más iconoclastas por ingenuidad que por convicción se arroguen las banderas del desfile, respaldados por las razones del día, las retóricas primarias que alzan las masas en los estadios y el coro de las ranas periodísticas. Lo repito, un día vendrá acaso en que el hombre pueda prescindir con pleno derecho de los intelectuales que conocimos y fuimos; pero hasta ese día, compañeros revolucionarios, que nadie venga a destruir sin saber antes cómo se construye, que nadie crea que la mera voluntad revolucionaria reemplaza sin pérdida esa larga paciencia enamorada que dio los poemas de este libro, que hizo de Vallejo y de Huidobro y de Neruda los padres de una palabra capaz de atacar los viejos órdenes y abritnos. ancha la puerta de este tiempo más nuestro y más hermoso.

Por cosas así, Pablo, me importa poco lo que hoy digas o digan de tus primeras Residencias. Hace ya muchos años que insisto monótonamente en que no llegaremos a cuajar nuestro destino legitimo - $\tan$ por encima del panorama envilecido por las alienaciones y los imperialismos- si no empezamos por bajar a lo más hondo de nosotros mismos, hombres y cosas, materias y palabras, ideales y tabúes, descriminaciones y machismos, banderas de pacotilla y nacionalismos de campeonato. Cómo no sentir entonces que tus primeras Residencias son en tu terreno de poeta esa bajada a los infiernos sin la cual jamás habrías retornado "a riveder le stelle". En la cuarta década del siglo, en un periodo en el que casi todos los poetas continuaban una vía lírica sin sorpresas, cae sobre una generación latinoamericana estupefacta, maravillada o enfurecida, un enorme aluvión de palabras cargadas de materia espesa, de piedras y de líquenes, de esperma sideral, de vientos litorales y gaviotas de fin de mundo, un inventario de ruinas y de nacimientos, una nomenclatura de ma- 
deras y metales y peines y mujeres y farallones y espléndidas borrascas, y todo eso, como tantas otras veces, desde el otro lado del mundo donde un poeta mira por encima del mar su Chile remotísimo y lo comprende y lo conoce tanto mejor que otros con las narices pegadas al cerro Santa Lucia o a los lagos australes. Porque ese Chile de las Residencias es ya el mundo latinoamericano abrazado en su totalidad por una poesía todopoderosa, y es también lo planetario, la suma de los mares y las cosas con un hombre solitario en su centro, el hombre viejo entre las ruinas de una historia que se desinfla not with a bang but a whimper, y el hombre viejo nace a su verdadera juventud, a su hombría ganada verso a verso, pena a pena, el hombre viejo deja a su espalda el catálogo frenético de amores y pesadumbres y tactos y sumersiones en el magma sin salida del individuo que reside en la tierta como Robinson en su isla, el hombre Neruda se alza desnudo y liberado, mira de frente y ve un pueblo en lucha, entra en la guerra de España como se entra en el mar al término del polvo y el sudor, Pablo puede escribir España en el corazón, Pablo está ya entre los hombres, el Canko General late en su sangre, él ya sabe que no estamos solos, que no man is an island, que ya nunca más estaremos solos en la isla Tierra.

Así, en mi juventud argentina, viví yo la avalancha prodigiosa de las primeras Residencias, así con Neruda y con Vallejo desperté a un sentimiento sudamericano que de golpe y soberanamente se bastaba a sí mismo, que no necesitaba filiaciones europeas para cumplirse. Cómo podría extrañarme que treinta años más tarde esa poesía de fundación se vea confirmada por otra avalancha de poesía, la de pueblos enteros alzándose contra una falsa historia; la revolución estaba ya en esas semillas de escándalo, la fundación de nuestra palabra propia era el signo más seguro de los actos que vendrían a corroborarla en una búsqueda de totalidad latinoamericana. Ya sé que estamos todavía lejos, Pablo, pero el futuro es nuestro, hermano, y pase lo que pase, tantos millones de hombres no hablaremos inglés. Dulce me es escribirte estas páginas a la hora en que tu tierra perfilada y envuelta en pájaros salinos entra en la arena del combate socialista. Ya ves, el negro ciclo elemental de las primeras Residencials puede quedar atrás como prefieres: otra poesía te llama y llama a tu pueblo. ¿Pero qué quiere decir atrás en la imaginación del eterno Prometeo humano? Las revoluciones nacen de una dialéctica más compleja de lo que alcanzan a analizar las calculadoras obedientes y programadas. Extraños objetos, materias no definibles, pulsaciones secretas son parte de su génesis, y poetas como tú son los sismógrafos de esa lenta resquebrajadura que un día será fuego y lava. No sé, Pablo, si esto que he tratado de explicar 
tendtá sentido para Christiane en Limoges, Raymond en Marsella o Robert en París. No sé si tus lectores franceses esperaban una introducción más sistemática y textual de tu poesía; desde luego puedo decirles que hay sobre ti una inmensa bibliografía en cualquier buena biblioteca, pero se me ocurre que no es necesario decirles eso, que Christiane y Raymond (a quienes imagino jóvenes y llenos de ese viento nuevo que a pesar de cachiporras y mentiras se abre paso en el cansado aire europeo) preferirán esta carta en la que no se habla de una poesía por sí misma sino de una mutación radical de nuestro lenguaje más profundo, de una obra que fundamenta, anuncia y apoya el encuentro del hombre latinoamericano consigo mismo, su residencia final en una tierra propia, en un mundo más justo y más hermoso.

Julio CORTÁzAr

Viena, septiembre de 1971 